\title{
Frog in a bucket
}

Distance learning.

"I'm not a real frog," said the frog.

Space Corps' founder and most celebrated explorer Horatio Strovic tapped his atmospheric O-meter. He was expecting hallucinations, but not this early in the process.

"I'm not going to talk to a 'not-real frog," he said, "even if it does pass the time before the air runs out."

"Would you honestly prefer me to be an all croaking, flyswallowing, living frog?" said the frog, sounding aggrieved. "You wouldn't get much of a conversation out of it. Trust me, I know."

"Look," said Strovic, exasperated at having to explain the nature of his own delusion to a delusion of his own. "You are merely a straightforward hallucination from the chemical build-up in my brain resulting from my air-scrubber having been sabotaged."

"Have it your own way Captain," and with that the frog said nothing further.

Strovic sort of expected the little apparition to vanish, but it persisted, sitting on his main-drive display, little froggy fingers resting on the coolant purge icon.

"Could you move over a bit, you're making me nervous, sitting just there."

"Captain, you have done remarkably well." The frog had obviously decided to try again. "Your ship is travelling at above 90\% of the speed of light, and because you're in a Magueijo fast-track, your relativistic speed is actually $103 \%$ of $c$." The frog sat back on his haunches and clapped his hands together in a little round of applause. "Congratulations Captain. You are the first human to break the light barrier."

It was true: Strovic's vessel, the Light Ship Highway, was technically travelling faster than light. She powered through a naturally occurring corridor of space where the speed of light was slightly different from that in the rest of the Universe; fossilized space-time from a period when $c$ had a higher value.

"Strictly speaking," said the frog. "We think that you've cheated. Your understanding of the Universe is based on the fallacy of relativity. You believe one of the most basic truths in the Universe to be impossible. Yet you still managed to hurl yourself into the void above the speed of light. Our laws state that you are now, by definition, civilized. Personally, I think you fluked it." "Well, thank you very much. I take it that you are the Galactic Welcoming Committee - I don't suppose you bought a new set of silver filters with you by any chance?"

"Sarcasm doesn't suit you, Captain," said the frog. "And I'm not from your galaxy, and we are separated by about a billion and a half years, but otherwise spot on."

Strovic looked closer at the little frog. It looked exactly like a tree frog, the sort that lives in bromeliads, but there was a hint of something sharp and intelligent in its bright red eyes. Hesitantly he reached out and gently prodded the creature. His fingers registered cold leathery skin, something like a congealed jelly.

"Why am I seeing a frog?" he asked.

"It's really very simple," said the frog. "The Universe is spinning. Does that give you a clue?"

"The Universe is not spinning," said Strovic. "And I refuse to believe it is just because a frog tells me so."

"Please yourself, but the truth is that the Universe is a finite physical structure made up as a super-fluid condensate. It has a physical boundary and a finite distance from edge to edge. The Universe and the spacetime condensate are entirely contained within what you charmingly refer to as a 'black hole'. Extra-universal space is to all intents and purposes infinite, so your whole Universe is a finite subset of an infinite data set.

Strovic blinked once.

"Tell me about Zeno, Captain Strovic."

"Zeno? The philosopher?"

"Yes Captain, the man who almost broke the light barrier when your world was wearing togas."

"You're the frog in the pond?"

"Ah," said the frog. "Light dawns."

"A frog in a pond swims towards the edge of the pond," began Strovic as if reciting. "But he first has to cover half of the distance, and then half of the remaining distance, and then half that distance and so on ad infinitum, but it's a paradox because the frog eventually does get to the edge."

"Doesn't that give you a clue about the nature of space?" The frog sounded a little exasperated. Strovic answered him with a blank shrug.

"Travelling across a finite distance there will always be a remainder left over," the frog insisted. "Therefore it is not possible to cover a finite distance."

"But we live in a space where this does not apply. Converging wotsits, and the Greeks not having a word for zero and all that."

"Hmmm, that sounds likely doesn't it?" sniffed the frog. "Work it out Horatio, you can do it. It's impossible to cross a finite distance. The Universe is a finite physical structure set in a non-finite space. Come on, Captain, make the leap."

"So what you're saying is that all distances within the Universe are a finite fraction of an infinite whole, and that a finite number divided by transfinite number is equal to zero, so therefore all distances must be equal to zero. The whole Universe exists within a singularity?"

The frog slapped one of his little hands over his face in a gesture of total exasperation.

"Well I suppose you've got time to work it out", he said.

"If you hadn't noticed," said Strovic a little more sharply than he intended. "I'll be dead in two hours time, sabotaged by the Orbital separatists.

"Oh didn't I mention?" said the frog innocently. "We've been on the lawn of the White House for the past five minutes. If you want a breath of fresh air, all you have to do is open the door.

"Welcome home Captain Strovic, you have a lot to think about."

With that the not-a-real frog disappeared in a little puff of not-smoke.

\section{Gareth Owens}

Gareth Owens is a palaeolinguist and a student of the arcane writings of ancient and lost civilizations. He is a composer, writer and traveller and has recently completed a novel. 